\title{
Sorption of pharmaceuticals residues from water to char (scrap tires) impregnated with amines
}

\author{
Katarzyna Styszko ${ }^{1, *}$, Paweł Baran ${ }^{1}$, Marta Sekuła ${ }^{1}$ and Katarzyna Zarębska ${ }^{1}$ \\ ${ }^{1}$ AGH University of Science and Technology, Faculty of Energy and Fuels, Al. Mickiewicza 30, \\ 30-059 Krakow, Poland
}

\begin{abstract}
The study investigated the application of char activated with $\mathrm{CO}_{2}$ and impregnated with amines solutions for removal of selected xenobiotics from aqueous solutions. The chars produced from the pyrolysis of waste tires. The solutions of monoethanolamine (MEA), diethanolamine (DEA) and polyethylenimine (PEI) were used for impregnation of char. The sorption capacity of char impregnated with amines depended on amines chemical properties. The adsorptive removal of mixture of pharmaceuticals residues by modified materials was assessed. BET surface area of materials varied from $36 \mathrm{~m}^{2} \mathrm{~g}^{-1}$ to $128 \mathrm{~m}^{2} \mathrm{~g}^{-1}$. The highest removal efficiencies up to $99 \%$ were observed for char impregnated with PEI.
\end{abstract}

\section{Introduction}

The development of civilization caused the increase of the amount of wastes. Waste tires have been making greater problem in global scale. An interesting method of their disposal is to surrender to the pyrolysis process [1]. As a result of the process we obtain two products: raw pyrolysis oil and pyrolytic solid fraction - char. The liquid product is characterized by a high content of aromatic hydrocarbons and can be used as heating fuel $[2,3]$. Simple mixing with rapeseed oil allows to obtain heating fuel with properties required for the fuel oil. The char can be used as an inactive filler in the rubber industry. The char may be also a valuable raw material for the production of activated carbon use as an adsorbent for removing various kinds of pollutants, both liquid and gas phase $[4,5]$. Pyrolysis of such waste tires and their use as sorbent, possible uses of waste tires as a source of raw materials or alternative fossil fuels are an attractive alternative to disposal [6].

Pharmaceuticals and another xenobiotics residues are not sufficient removed in wastewater treatment plants [7-12]. It is important to develop and improve technologies for the removal of such compounds to ensure a sustainable healthy natural environment [1316]. In recent years, many studies have been devoted to investigate the application of char for pollutants removal from aqueous solutions [5,17-19]. Chemical recycling of waste materials is indeed of scientific importance from the perspective of realizing effective waste management [20-31]. The porous structure of activated carbons and the presence of surface

\footnotetext{
* Corresponding author: styszko@agh.edu.pl
} 
groups containing heteroatoms are the principal physical and chemical properties that will determine their performance as adsorbents. The polarity, solubility and molecular size of the adsorbate and the $\mathrm{pH}$ of the solution are other important factors that need to be taken into account when assessing the effectiveness of an adsorbent [1]. There are many structural varieties of pharmaceuticals residues that can be classified as either ionic or nonionic. This is one of the reasons why it is important to study the surface chemistry of the activated carbons used to eliminate them. Impregnation of selected materials is one of the possibility for preparing novel organic pollutants adsorbents. However until now little work has been carried out on the use of char (scrap tires) as adsorbent of pharmaceuticals residues [32]. According to the best knowledge of authors, char (scrap tires) impregnated with amines has been used for the first time for adsorption of pharmaceuticals residues. The objective of this study was therefore to find out if the impregnation with amines improves sorption properties of char.

\section{Materials and methods}

\subsection{Materials}

Table 1 provides the physical and chemical properties of target waste water pollutants investigated in this study. All reference standards were of $>98 \%$ purity and were purchased from Sigma Aldrich (Saint Louis, USA).

Table 1. Characteristics of the compounds

\begin{tabular}{|c|c|c|c|c|c|}
\hline Group & Compound & Molecular structure & MW & $\mathbf{p K a}_{\mathrm{a}}$ & Log Kow \\
\hline \multirow[t]{5}{*}{ Analgesics } & $\begin{array}{l}\text { Ibuprofen } \\
\text { (IBF) }\end{array}$ & & 206,28 & 4.9 & $3.5-4.0$ \\
\hline & $\begin{array}{l}\text { Acetaminophen } \\
\text { (ATP) }\end{array}$ & & 151.16 & 9.4 & $0.5-0.9$ \\
\hline & $\begin{array}{l}\text { Ketoprofen } \\
\text { (KTP) }\end{array}$ & & 254.28 & 4.5 & $3.1-3.6$ \\
\hline & $\begin{array}{l}\text { Naproxen } \\
\text { (NPK) }\end{array}$ & & 230.26 & 4.2 & $3.2-3.3$ \\
\hline & $\begin{array}{l}\text { Diclofenac } \\
\text { (DCF) }\end{array}$ & & 318.10 & 4.2 & $4.2-4.5$ \\
\hline \multirow[t]{2}{*}{ Metabolites } & $\begin{array}{l}\text { Salicylic acid } \\
\text { (SAL) }\end{array}$ & & 138.12 & 3.0 & $2.3-2.4$ \\
\hline & $\begin{array}{l}\text { Clofibric acid } \\
\text { (CFA) }\end{array}$ & & 214.65 & 3.18 & 2.6 \\
\hline Stimulant & $\begin{array}{l}\text { Caffeine } \\
\text { (CAF) }\end{array}$ & & 194.20 & 10.4 & -0.07 \\
\hline Antiepileptic drug & $\begin{array}{l}\text { Carbamazepine } \\
\text { (CBZ) }\end{array}$ & & 236.27 & 13.9 & $2.4-2.9$ \\
\hline$\beta$-Blocker & $\begin{array}{l}\text { Propranolol } \\
\text { (PPN) }\end{array}$ & & 259.35 & 9.4 & $2.7-3.6$ \\
\hline
\end{tabular}

Solutions of the compounds both single ones and as mixtures were prepared in ethyl acetate and stored in the dark at $4{ }^{\circ} \mathrm{C}$. A stock standard solution of $1000 \mu \mathrm{g} \mathrm{mL}^{-1}$ of each compound was used to prepare a standard mixture solution. Mixtures were used to spike 
water samples. A four ring polycyclic aromatic phenol, 1-pyrenol (>99\%), was used as an internal standard and was purchased from Sigma-Aldrich (Saint Louis, USA).

Derivatization reagent BSTFA $+1 \%$ TMCS was purchased from Supelco (Bellefonte, USA). Analytical grade reagents $\mathrm{CaCl}_{2}, \mathrm{HCl}$, and methanol (HPLC grade) and ethyl acetate (for GC analysis) were obtained from Avantor Performance Materials Poland S.A. (Gliwice, Poland). Deionized water $\left(<0.07 \mathrm{~S} \mathrm{~cm}^{-1}\right)$ was used to prepare sample solvents for extraction experiments and the solid-phase extraction (SPE) was obtained from the HLP5 pure water system (Hydrolab, Gdansk, Poland). Oasis HLB 3cc extraction cartridges, (60mg) for SPE were purchased from Waters (Wexford, Ireland). Measurements of $\mathrm{pH}$ were carried out using a multimeter from Crison Instruments (Barcelona, Spain).

\subsection{Characterisation of char and their modification}

Waste tire fragments $(50 \times 50 \mathrm{~mm})$ were carbonized at $673 \mathrm{~K}$ and activated with $\mathrm{CO}_{2}$ at $1273 \mathrm{~K}$ for 15 minutes, based on procedure presented by Baran et al. [21]. Activated coal samples (CHAR) then underwent wet impregnation with nitrogen compounds solutions monoethanolamine (MEA), diethanolamine (DEA) and polyethylenimine (PEI) (concentration was $1.5 \mathrm{~mol} \mathrm{~L}^{-1}$ ). The impregnated samples were dried at $378 \mathrm{~K}$ for $1 \mathrm{~h}$.

A Micromeritics Accu Pyc 1330 pycnometer was used for helium density analyses of all the samples at $296 \mathrm{~K}$. To determine the influence of activation and impregnation on the specific surface area, BET method, low temperature nitrogen $\left(\mathrm{N}_{2}\right)$ adsorption isotherms for all of the samples were used. The measurements were made at liquid nitrogen temperature $(77 \mathrm{~K})$ using a Quantachrome Instruments Autosorb 1-C.

Helium density analysis results are presented in Table 2. The activation process resulted in increased carbon material density. Density changes may indicate the implantation of introduced substances into the samples.

Table 2. Selected properties of sorbents

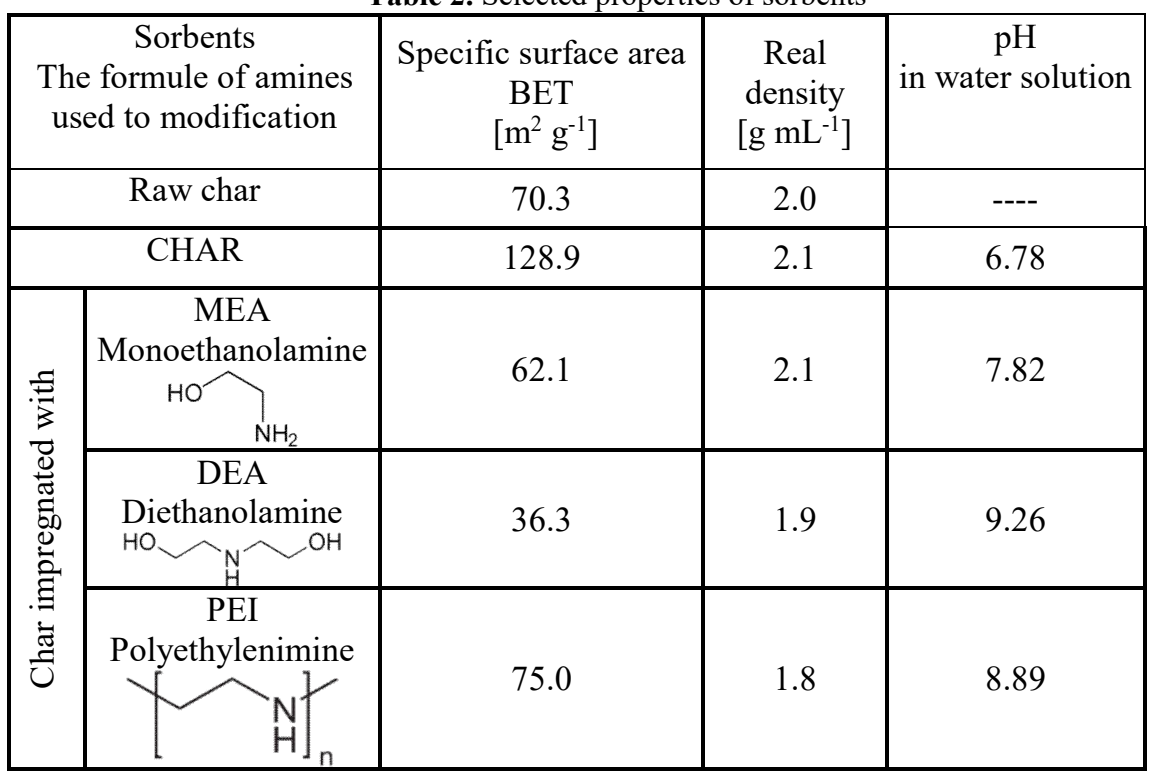

Low-temperature nitrogen-sorption-specific surface area measurements revealed relatively low values for raw char. After activation, the value increased from 70 to $128.9 \mathrm{~m}^{2}$ $\mathrm{g}^{-1}$. Analogous measurements were performed for selected samples impregnated with MEA 
DEA and PEI. BET results for MEA, DEA and PEI samples indicated that the specific surface areas had decreased. In the case of sample PEI, the specific surface area is the highest among impregnated samples. Reducing specific surface area of the impregnated samples indicates that the porous structure has been blocked. Thus, it changes the chemical nature of the sorbent surface, and it may be important for the adsorption of pharmaceuticals residues.

\subsection{Sorption experiments}

Sorption experiments were performed according to OECD Guideline 106 [33]. Batch sorption experiments of selected compounds were conducted in $20 \mathrm{~mL}$ vials containing 50 $\mathrm{mg}$ of char in a $10 \mathrm{~mL}$ solution of $0.01 \mathrm{M} \mathrm{CaCl}_{2}$ to minimize the cation exchange. Preconditioning of the char/water suspension for $21 \mathrm{~h}$ was conducted in $\mathrm{CaCl}_{2}$ solution. Then the suspension was spiked with an appropriate working multi standard solution (50 $\mu \mathrm{L}, 40 \mu \mathrm{g} \mathrm{mL}^{-1}$ ) to reach $0.2 \mu \mathrm{g} \mathrm{mL}^{-1}$ and shaken for $24 \mathrm{~h}$ using a horizontal shaker at 50 $\mathrm{rpm}$. Afterwards, the solutions were filtered and analyzed.

Blank and control solutions were performed in parallel with each sample. The blank and control solutions were shaken and analyzed with the same procedure as all other samples. Blank solutions included the same amount of respective sorbents as the real samples. Control samples were processed to estimate the process efficiency - the combination of the losses of tested compounds due to the adsorption on glass surface during experiments and recovery of analytes from the matrix by the samples extraction process. Control samples contained the same volume of supernatants and the mixture of standard solution but no sorbents. All experiments were performed in duplicates, each solution was analyzed two times and the obtained values were averaged.

The capacity of adsorption $\left(\mu \mathrm{g} \mathrm{g}^{-1}\right)$ was calculated by using the following equation:

$$
\mathrm{Q}=\left(\left(\mathrm{C}_{0}-\mathrm{C}_{\mathrm{eq}}\right) \mathrm{V}\right) / \mathrm{m}_{\mathrm{s}}
$$

where $\mathrm{C}_{0}$ is the initial emerging contaminant concentration and $\mathrm{C}_{\mathrm{eq}}$ is the emerging contaminant concentration $\left(\mu \mathrm{g} \mathrm{mL}^{-1}\right)$ at equilibrium, $\mathrm{V}$ the volume of solution $(\mathrm{mL})$ and $\mathrm{m}_{\mathrm{s}}$ is the mass of the sorbent $(\mathrm{g})$.

\subsection{Analytical procedures}

The supernatants obtained after filtration through a $0.2 \mu \mathrm{m}$ glass fiber syringe filter were acidified to a $\mathrm{pH}$ of 2.0 and successively extracted by using Oasis HLB cartridges.

Analyses were carried out with the usage of Thermo Scientific GC Trace 1300 gas chromatograph coupled to the ITQ 900 ion trap mass spectrometer and a TriPlus RSH autosampler. The flow of helium through a GC column was constant and set at $1 \mathrm{ml} \mathrm{min} \mathrm{m}^{-1}$. The programmable temperature of the vaporization injector was maintained at $250{ }^{\circ} \mathrm{C}$, the transfer line at $280{ }^{\circ} \mathrm{C}$ and the ion source at $250{ }^{\circ} \mathrm{C}$. The injector was operated at splitless conditions for $1 \mathrm{~min}$, then turned to the split mode at the ratio of 50:1. Volume of injections was $1 \mu \mathrm{L}$. All the compounds separations were performed on a TG-SQC capillary column from Thermo Scientific that had $30 \mathrm{~m}$ x $0.25 \mathrm{~mm}$ inner diameter and a film thickness of $0.25 \mu \mathrm{m}(5 \%$ phenyl $95 \%$ dimethylpolysiloxane). The temperatures program was as follows: $70{ }^{\circ} \mathrm{C}$ for $2 \mathrm{~min}$, from $70{ }^{\circ} \mathrm{C}$ to $320{ }^{\circ} \mathrm{C}$ at $20{ }^{\circ} \mathrm{C} \mathrm{min}-1$, and finally $5 \mathrm{~min}$ at $320{ }^{\circ} \mathrm{C}$. The analyses were performed in positive mode, an electron energy $70 \mathrm{eV}$ and emission current $250 \mu \mathrm{A}$. Helium (99.999\%) was used a collision gas with flow $0.3 \mathrm{~mL} \mathrm{~min}^{-1}$.

Mass spectrometry analyses were performed in the multi reaction monitoring (MRM) mode measuring the fragmentation of the precursor ions. The choice of fragmentation 
products for each substance was based on the most intense signal. For the acquisition of the MRM transitions the analytical run was split into time windows considering the expected retention time of the selected compounds. Data was collected, analysed and processes using Thermo Xcalibur.

Compounds were quantified by MRM, using the highest characteristic precursor ion/product ion transitions and characteristic ions used are listed in Table 2. Specific and intense product ions of each target analyte were used for quantification, and a secondary product ion was used as qualifier ion for confirmatory purposes. The absolute recoveries for water samples in each sample series were determined by comparing the peak area of the compound in each control sample, to the area obtained from detecting a standard solution prepared in the same solvent mixture. The concentrations of the compounds were corrected using the recovery percentages. The method quantification limits (MQL) for all analytes ranged from 0.6 to $8 \mathrm{ng} \mathrm{L}^{-1}$. Depending on the compound, the absolute recoveries ranged from 67 to $147 \%$ (see Table 3).

Table 3. Retention times, MS/MS parameters for the analysis of the chosen xenobiotics by GCMS/MS, method quantification limits, R2 and SPE recoveries.

\begin{tabular}{|l|l|l|l|l|l|l|}
\hline Compound & RT (min) & $\begin{array}{l}\text { Precursor-ion } \\
\mathrm{m} / \mathrm{z}\end{array}$ & $\begin{array}{l}\text { Product-ions } \\
\text { Quantification } \\
\text { /confirmation } \\
\mathrm{m} / \mathrm{z}\end{array}$ & $\mathrm{R}^{2}$ & $\begin{array}{l}\text { MQL } \\
\text { ng L-1 }\end{array}$ & $\begin{array}{l}\text { SPE } \\
\text { absolute } \\
\text { recovery } \\
(\%)\end{array}$ \\
\hline Salicylic acid & 8.27 & 267 & $209 / 249$ & 0.993 & 0.7 & 87 \\
\hline Clofibric acid & 8.69 & 143 & $99 / 115$ & 0.997 & 3.0 & 108 \\
\hline Ibuprofen & 8.96 & 160 & $145 / 117$ & 0.992 & 3.0 & 122 \\
\hline Acetaminophen & 9.04 & 280 & $206 /-$ & 0.989 & 0.6 & 91 \\
\hline Caffeine & 10.48 & 194 & $165 / 109$ & 0.986 & 5.0 & 67 \\
\hline Naproxen & 11.49 & 185 & $170 / 153$ & 0.998 & 0.4 & 136 \\
\hline Propranolol & 11,92 & $72,223(\mathrm{SIM})$ & - & 0.994 & 8.0 & 139 \\
\hline Ketoprofen & 12.10 & 282 & $253 / 266$ & 0.997 & 3.0 & 88 \\
\hline Carbamazepine & 12.42 & 193 & $165 / 191$ & 0.990 & 0.9 & 129 \\
\hline Diclofenac & 12.49 & 214 & $179 / 151$ & 0.993 & 1.5 & 147 \\
\hline
\end{tabular}

\section{Results and discussion}

Fig. 1 shows the sorption efficiency of all tested pharmaceuticals residues to char and its modification impregnated of amines. The sorption of analytes onto char ranged from $36 \%$ to almost $100 \%$. The impregnated char with polyethylenimine (PEI) exhibited the highest sorption for all analytes, except propranolol. For the removal of propranolol, char impregnated with diethanolamine (DEA) was the most sufficient, up to $79 \%$. The highest sorption, above $85 \%$, without regard to kind of sorbent, was observed for naproxen, diclofenac, carbamazepine, acetaminophen and ibuprofen. Not without meaning is the increasing basicity of used for impregnation amines, which is proved by the highest sorption capacity in case of use of PEI. The tested compounds are amphoteric species and consist of single or multiple charged groups, as well as polar groups (hydroxyl, carbonyl, carboxyl, amine) with aromatic rings. The sorption of salicylic acid and ketoprofen decrased on char impregnated monoethanolamine (MEA) and diethanolamine (DEA), and not changed for clofibric acid. Salicylic acid and clofibric acid characterized the lowest values of $\mathrm{pK}_{\mathrm{a}}$. Acidic pharmaceuticals in solutions at neutral and alkaline $\mathrm{pH}$ are present in the ionic forms. This might be related to repulsive interactions between functional group of compounds and on the sorbent's surface. Similar interactions, although significantly weaker, was noted for ibuprofen and diclofenac, both acidic compounds. 


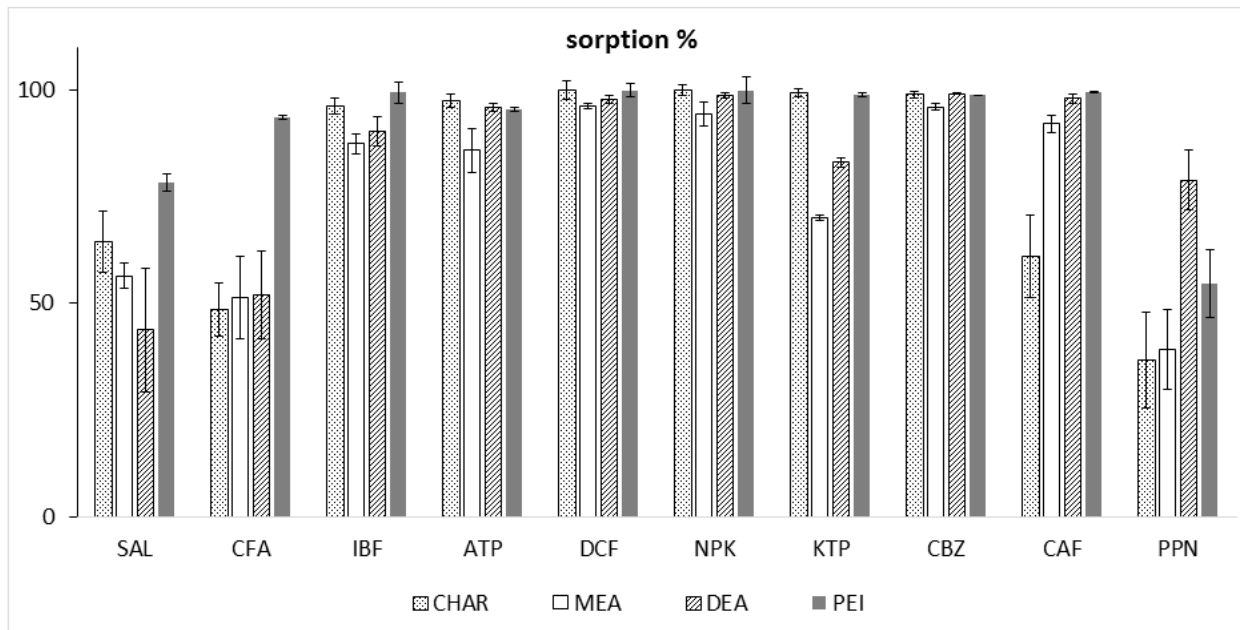

Fig. 1. Sorption of pharmaceuticals residues on char and its modifications with amines

At $\mathrm{pH}$ values their $\mathrm{pK}_{\mathrm{a}}$, the sorption affinity toward adsorbents increased significantly with the $\mathrm{pH}$ [13], whereas the sorption affinity dropped sharply at the $\mathrm{pH}$ above the $\mathrm{pK}_{\mathrm{a}}$ values. This effect occurs in particular for char impregnated with MEA and DEA. Whereas less variation of sorption affinity due to their higher $\mathrm{pK}_{\mathrm{a}}$ values (less variation in the ionic state from neutral to ionized form) allows carbamazepine, caffeine, acetaminophen to show strong hydrophobic interactions throughout a wide range of $\mathrm{pH}$ values. The octanol-water partition coeffient $\mathrm{K}_{\mathrm{OW}}$ has been used to represent hydrophobicity. This is accurate if the compounds are non-ionizable, independent of $\mathrm{pH}$. Under the condition of dominant hydrophobic interaction in the sorption study of higher-aromatic-containing sorbents, ionized molecules hardly attract to sorbent through this mechanism. Hovewer, the sorption studies of organic compounds in various solutions cannot be interpreted by one or two mechanisms.

Application of polar compounds of unsaturated bounds on the surface of porous material, significantly improved effectiveness of contaminations sorption. The above results demonstrated that impregnation only with amine group (PEI) allowed a higher sorption for all pharmaceuticals residues, than impregnation with amine and hydroxyl groups (MEA and DEA). PEI is a cationic polymer; the negatively charged compounds are attracted to sorbents coated in PEI. Similar observation to higher adsorption capacity toward endocrine disrupting compounds and pharmaceuticals was reported by Jung et al. [34] for N-biochar. The impregnation with compounds contains hydroxyl groups is significant for sorption of analytes with amine group in their structure as propranolol and acetaminophen. Most of applied pharmaceuticals due to the presence of hydroxyl and carboxyl groups are characterized by acidic properties, which can indicate specific mechanism of interaction or chemisorption taking place on the impregnated sorbent. As a result of the impregnation process, the pores were blocked, however decreasing the specific surface area has not influence on the sorption of analytes. The pharmaceuticals molecules are characterized by large dimensions, therefore the application of microporous adsorbents not always can be effective.

The variation in capacity of sorption of each compound to tested sorbents is given in Table 4. Sorption capacity ranged from $9.1 \mu \mathrm{g} \mathrm{g}^{-1}$ (propranolol) to $39.9 \mu \mathrm{g} \mathrm{g}^{-1}$ (diclofenac). After 24 h, 54 - 99\% of the compounds sorbed to char impregnated with polyethylenimine. The high sorption capacity of sorbent impregnated with PEI at $\mathrm{pH} 8.9$ is important for wastewater treatment plants, which generally operate at $\mathrm{pH} 8$. 
Table 4. The capacity of sorption $\left(\mu \mathrm{g} \mathrm{g}^{-1}\right)$ of pharmaceuticals residues to char and its modifications with amines

\begin{tabular}{l|cccc}
\hline & $\boldsymbol{C H} \boldsymbol{A} \boldsymbol{R}$ & $\boldsymbol{M E} \boldsymbol{A}$ & $\boldsymbol{D E} \boldsymbol{A}$ & $\boldsymbol{P E I}$ \\
\hline SAL & $25.8 \pm 4.0$ & $22.6 \pm 1.4$ & $20.1 \pm 5.2$ & $31.3 \pm 1.1$ \\
CFA & $19.4 \pm 3.5$ & $20.5 \pm 4.4$ & $20.8 \pm 4.7$ & $33.2 \pm 4.9$ \\
IBF & $34.8 \pm 4.3$ & $34.9 \pm 1.1$ & $36.0 \pm 1.6$ & $39.1 \pm 0.7$ \\
ATP & $35.7 \pm 3.9$ & $34.3 \pm 2.3$ & $38.3 \pm 0.4$ & $37.7 \pm 0.6$ \\
KTP & $39.1 \pm 0.9$ & $28.0 \pm 2.1$ & $33.2 \pm 2.8$ & $38.7 \pm 1.0$ \\
NPK & $39.5 \pm 0.4$ & $37.7 \pm 1.3$ & $39.5 \pm 0.3$ & $39.8 \pm 0.1$ \\
DCF & $39.6 \pm 0.5$ & $38.5 \pm 0.3$ & $39.1 \pm 0.5$ & $39.9 \pm 0.1$ \\
CAF & $19.3 \pm 5.4$ & $34.8 \pm 1.5$ & $39.1 \pm 0.5$ & $39.5 \pm 0.4$ \\
CBZ & $39.2 \pm 0.5$ & $38.3 \pm 0.3$ & $39.6 \pm 0.1$ & $38.5 \pm 1.2$ \\
PPN & $10.2 \pm 0.8$ & $15.7 \pm 2.8$ & $31.5 \pm 3.3$ & $21.8 \pm 3.9$ \\
\hline
\end{tabular}

The current work is significant from an environmental perspective in that it provides a basis or future studies which may look at other environmental variables affecting sorption processes. The sorption data can be useful in predicting ecological risks of potential compounds from different therapeutic groups and metabolites through the understanding their transport in natural organic matter.

\section{Conclusions}

For the sorbents received as a result of process of activation and impregnation, the usefulness of its application for the removal of pharmaceuticals from water was investigated, based on the GC-MS analysis. The results of analysis showed, that the most effective and universal sorbent for the removal of pharmaceuticals from water among tested ones is the char impregnated with PEI, as the least compound adsorbed amount was over $50 \%$. The smallest values of sorption capacity were found in case of non-impregnated char, which proves the hypothesis that nitrogen compounds used for the impregnation improved sorption capacity of received chars. The formation of hydrogen bound is probable between amine group of impregnating agent and hydroxyl group present in the pharmaceuticals and metabolites. Confirmation for this is the increase in sorption capacity along with the increase in sorbate acidity.

Acknowledgment: This work was supported by AGH University Grant no 11.11.210.244. Some of the measurements were performed using the scientific equipment belonging to the laboratories of AGH-UST Energy Centre Cracow, Poland.

\section{References}

1. B. Acevedo, C. Barriocanal, I. Lupul, G. Gryglewicz, Fuel 151, (2015).

2. L. Zhang, B. Zhou, P. Duan, F. Wang, Y. Xu, Chem. Eng. J. 285, (2016).

3. I. Hita, M. Arabiourrutia, M. Olazar, J. Bilbao, J.M. Arandes, P. Castaño, Renewable and Sustainable Energy Reviews 56, (2016).

4. A.S. Al-Rahbi, P.T. Williams, Waste Manage. (Oxford) 49, (2016).

5. S. Uçar, S. Karagöz, Fuel 137, (2014).

6. M. Sienkiewicz, J. Kucinska-Lipka, H. Janik, A. Balas, Waste Manage. (Oxford) 32, 10 (2012).

7. K. Nosek, K. Styszko, J. Gołaś, International Journal of Analytical Environmental Chemistry 94, 10 (2014).

8. M. Petrović, S. Gonzalez, D. Barceló, TrAC, Trends Anal. Chem. 22, 10 (2003). 
9. C.I. Kosma, D.A. Lambropoulou, T.A. Albanis, J. Hazard. Mater. 179, 1-3 (2010).

10. R.A. Hamza, O.T. Iorhemen, J.H. Tay, Environmental Technology \& Innovation 5, (2016).

11. S. Castiglioni, R. Bagnati, R. Fanelli, F. Pomati, D. Calamari, E. Zuccato, Environ. Sci. Technol. 40, 1 (2005).

12. B. Kasprzyk-Hordern, R.M. Dinsdale, A.J. Guwy, Water Res. 43, 2 (2009).

13. K. Styszko, K. Nosek, M. Motak, K. Bester, Comptes Rendus Chimie 18, 10 (2015).

14. S.M. Rivera-Jimenez, M.M. Lehner, W.A. Cabrera-Lafaurie, A.J. HernándezMaldonado, Environmental Engineering Science 28, 3 (2011).

15. M. Grassi, G. Kaykioglu, V. Belgiorno, G. Lofrano, in: G. Lofrano (Ed.), Emerging Compounds Removal from Wastewater, Springer Netherlands, 2012, p. 15.

16. M.B. Ahmed, J.L. Zhou, H.H. Ngo, W. Guo, N.S. Thomaidis, J. Xu, J. Hazard. Mater. 323, Part A, (2017).

17. X. Tan, Y. Liu, G. Zeng, X. Wang, X. Hu, Y. Gu, Z. Yang, Chemosphere 125, (2015).

18. E. Kim, C. Jung, J. Han, N. Her, C.M. Park, M. Jang, A. Son, Y. Yoon, Journal of Industrial and Engineering Chemistry 36, (2016).

19. E.M. Cuerda-Correa, J.R. DomĂnguez-Vargas, F.J. Olivares-MarĂn, J.B.n. de Heredia, J. Hazard. Mater. 177, 1-3 (2010).

20. K. Styszko, A. Drobniak, Ochrona Środowiska 37, 1 (2015).

21. P. Baran, M. Krzak, K. Zarębska, J. Szczurowski, W.A. Żmuda, Przem. Chem. 96, 6 (2016).

22. M. Wdowin, M. Franus, R. Panek, L. Badura, W. Franus, Clean Technologies and Environmental Policy 16, 6 (2014).

23. L. Bandura, W. Franus, R. Panek, M. Wdowin, Global Journal on Advances Pure and Applied Sciences 1, (2013).

24. W. Franus, M. Wdowin, M. Franus, Environ. Monit. Assess. 186, 9 (2014).

25. M.K. Swarcewicz, J. Sobczak, W. Pazdzioch, Water Sci. Technol. 67, 6 (2013).

26. J. Heo, J.R.V. Flora, N. Her, Y.G. Park, Jaeweon Cho, A. Son, Y. Yoon, Sep. Purif. Technol. 90, (2012).

27. I. Ali, M. Asim, T.A. Khan, J. Environ. Manage. 113, (2012).

28. K. Bester, S. Banzhaf, M. Burkhardt, N. Janzen, B. Niederstrasser, T. Scheytt, Chemosphere 85, 8 (2011).

29. J. Xu, W. Chen, L. Wu, A.C. Chang, J Environ Qual 38, 3 (2009).

30. T.X. Bui, H. Choi, J. Hazard. Mater. 168, 2-3 (2009).

31. Y. Zhou, L. Zhang, Z. Cheng, J. Mol. Liq. 212, (2015).

32. R. Acosta, V. Fierro, A. Martinez de Yuso, D. Nabarlatz, A. Celzard, Chemosphere 149, (2016).

33. OECD, Test No. 106: Adsorption -- Desorption Using a Batch Equilibrium Method, (OECD Publishing, 2006).

34. C. Jung, J. Park, K.H. Lim, S. Park, J. Heo, N. Her, J. Oh, S. Yun, Y. Yoon, J. Hazard. Mater. 263, Part 2, (2013). 